OPEN ACCESS

ISSN 2548-2246 (online) ISSN 2442-9139 (print)

Edited by:

Paramitha Amelia K

Reviewed by:

Evi Wahyuntari

*Correspondence:

Dewi Aprilia Ningsih

dewiaprilianingsih.i@gmail.com

Received: 17 Desember 2019

Accepted: 20 Desember 2019

Published: 05 April 2020

Citation:

Aprilia Ningsih D, S and Mulyani D

(2020) Hubungan Pengetahuan

Dengan Perilaku Seksual Ibu Hamil

Trimester III Di Wilayah Kerja

Puskesmas Basuki Rahmad Kota

Bengkulu.

Midwiferia Jurnal Kebidanan. 6:1. doi: $10.21070 /$ midwiferia.v\%vi\%i.45
Hubungan Pengetahuan Dengan Perilaku Seksual Ibu Hamil Trimester III Di Wilayah Kerja Puskesmas Basuki Rahmad Kota Bengkulu

\section{The Relationship Of Knowledge With Sexual Behavior Pregnant Woman Trimester III In The Work Area Of Puskesmas Basuki Rahmad Bengkulu City}

\author{
Dewi Aprilia Ningsih*, Sanisahhuri, Dwi Mulyani \\ Program Studi D-IV Kebidanan, Sekolah Tinggi Ilmu Kesehatan Tri Mandiri Sakti Bengkulu, Bengkulu, Indonesia,
}

Sexual intercourse will be better done in the third trimester because the physical and mental conditions of pregnant women support, of course with the right sexual position. This study aims to study the relationship of knowledge with sexual behavior of pregnant women in third trimester in the working area of Puskesmas Basuki Rahmad Bengkulu City. This study uses a cross sectional design. The population in this study were all pregnant women in the third trimester in the working area of the health center, Basuki Rahmad, Bengkulu City. Sample appearance technique in this study uses purposive sampling. A sample of 35 third trimester pregnant women was obtained. data collection in this study uses a questionnaire. The results were obtained: $15(42.9 \%)$ respondents had good knowledge, 24 (68.6\%) respondents had sexual intercourse during the third trimester of pregnancy. There was a significant relationship between the knowledge of third trimester pregnant women with third trimester pregnant women sexual behavior. in the Puskesmas Basuki Rahmad Working Area, the City of Bengkulu with the category of moderate relations. It is expected that health workers increase information about sexuality during pregnancy to pregnant women, either by providing IEC at prenatal care visits or counseling and during posyandu visits.

Keywords: Knowledge, Sexual Behavior, Third Trimester

Hubungan seksual akan lebih baik dilakukan pada trimester III karena kondisi fisik dan mental ibu hamil mendukung, tentunya dengan posisi seksual yang tepat. Penelitian ini bertujuan untuk mempelajari Hubungan Pengetahuan dengan Perilaku Seksual Ibu Hamil Trimester III di Wilayah Kerja Puskesmas Basuki Rahmad Kota Bengkulu. Penelitian ini menggunakan desain cross sectional. Populasi dalam penelitian ini adalah semua ibu hamil trimester III, sampel diambil menggunakan teknik purposive sampling sebanyak 35 responden. Pengumpulan data menggunakan data primer dengan kuisioner. Hasil penelitian didapatkan ada hubungan yang signifikan antara pengetahuan 
ibu hamil trimester III dengan perilaku seksual ibu hamil trimester III di Wilayah Kerja Puskesmas Basuki Rahmad Kota Bengkulu dengan katagori hubungan sedang. Diharapkan kepada tenaga kesehatan agar meningkatkan informasi tentang seksualitas selama kehamilan kepada ibu hamil baik dengan cara memberikan KIE pada kunjungan pemeriksaan kehamilan maupun penyuluhan pada saat kunjungan posyandu.

Keywords: Knowledge, Sexual Behavior, Third Trimester

\section{PENDAHULUAN}

Kehamilan adalah suatu mata rantai yang berkesinambungan yang terdiri dari ovulasi (pematangan sel) lalu pertemuan ovum (sel telur) dan spermatozoa (sperma) terjadilah pembuahan dan pertumbuhan zigot kemudian bernidasi (penanaman) pada uterus dan pembentukan plasenta dan tahap akhir adalah tumbuh kembang hasil konsepsi sampai aterm (Manuaba and Dkk (2012)). Kehamilan terbagi menjadi 3 trimester, dimana trimester kesatu berlangsung dalam 12 minggu, trimester kedua 15 minggu (minggu ke- 13 hingga ke- 27), dan trimester ketiga 13 minggu (minggu ke- 28 hingga ke- 40) (Kebidanan (2014)).

Seksualitas memiliki arti yang lebih luas yakni bagaimana seseorang merasa tentang diri mereka dan bagaimana mereka mengkomunikasikan perasaan tersebut kepada orang lain melalui tindakan yang akan dilakukannya seperti sentuhan, pelukan, ataupun perilaku yang lebih halus seperti isyarat gerak tubuh, cara berpakaian dan perbedaan kata, termasuk fikiran, pengalaman, nilai, fantasi, dan emosi (K (2013) ). Kebutuhan akan hubungan seksual bagi suami istri didalam kehidupan rumah tangga merupakan unsur penting yang dapat meningkatkan kedekatan dan kualitas hidup (Cedli (2012)).

Hubungan seks selama kehamilan adalah hubungan suami istri yang dilakukan pada masa kehamilan dengan cara atau proses dari hubungan suami istri tersebut. Dengan memahami dan mengerti proses dalam hubungan seks selama kehamilan dapat mengurangi kecemasan dan ketakutan pada pasangan. Karena kehamilan itu sendiri membawa perubahan fisik, psikis dan sosial bagi pasangannya. Namun tentunya perubahan-perubahan itu tdak perlu mengganggu aktifitas sehari-hari dalam kehidupan seks pasangan (Hety (2016)).

Pola hubungan seksual ibu hamil trimester III dipengaruhi oleh hormon progesteron, dimana wanita akan merasa pusing, lemas dan gairah seksual menurun, pada fase ini wanita akan malas melakukan hubungan seksual. Melakukan hubungan seksual selama kehamilan memang tidak masalah, tetapi hendaknya disesuaikan dengan kondisi wanita tersebut agar terasa nyaman di kedua pihak pasangan. Dimana melakukan hubungan seksual akan lebih baik di lakukan pada trimester III karena kondisi fisik dan mental ibu hamil mendukung, tentunya dengan posisi seksual yang tepat (Kusmiyati (2010)).

Penelitian yang dilakukan oleh (Pramudawardhani and Shanti (2017)) menyebutkan bahwa berdasarkan hasil penelitian diketahui tingkat pengetahuan tentang posisi hubungan seksual selama kehamilan dalam kategori cukup dengan jumlah 25 responden (41,7\%). Hasil penelitian mayoritas ibu hamil menyatakan menganggap tabu hal tersebut dan kurang berminat untuk mencari informasi yang lebih akurat tentang posisi hubungan seksual yang diperbolehkan.

Hasil survei awal yang dilakukan di Puskesmas Basuki Rahmad Kota Bengkulu dengan memberikan kuesioner dari 10 orang ibu hamil trimester III terdapat 5 orang yang memiliki pengetahuan kurang 4 diantaranya tidak melakukan hubungan seksual selama kehamilan trimester III, 2 orang ibu memiliki pengetahuan yang cukup dan 3 orang ibu memiliki pengetahuan yang baik.

Berdasarkan uraian di atas peneliti ingin mengetahui hubungan antara pengetahuan dengan perilaku seksual ibu hamil Trimester III selama kehamilan di wilayah kerja Puskesmas Basuki Rahmad Kota Bengkulu. 


\section{METODE}

Desain penelitian adalah studi korelasi dengan pendekatan cross sectional. Penelitian dilakukan pada tanggal 17 Juli - 16 Agustus 2018. Populasi dalam penelitian ini adalah semua ibu hamil Trimester III yang ada di wilayah kerja Puskesmas Basuki Rahmad Kota Bengkulu pada tanggal 17 Juli - 16 Agustus 2018 sebanyak 50 responden. Sampel diambil dengan cara purposive sampling dimana sampel yang didapatkan selama waktu penelitian sebanyak 35 responden. Penelitian ini menggunakan data primer yang diperoleh dengan cara menyebarkan kuesioner dan data sekunder untuk melihat rekam medis register ibu hamil Trimester III Puskesmas Basuki Rahmad Kota Bengkulu. Data dianalisis menggunakan analisis univariat dan analisis bivariat menggunakan uji Chi-Square $\left(c^{2}\right)$ dan untuk mengetahui keeratan hubungan digunakan uji Contingency Coefficient (C).

\section{METODE}

\section{Hasil Univariat}

TABLE 1 | Distribusi Frekuensi Pengetahuan Ibu Hamil Trimester III di Wilayah Kerja Puskesmas Basuki Rahmad

\begin{tabular}{lll}
\hline Pengetahuan Ibu Hamil & Frekuensi & Persentase (\%) \\
\hline Kurang & 6 & 17,1 \\
Cukup & 14 & 40,0 \\
Baik & 15 & 42,9 \\
Total & 35 & 100,0 \\
\hline
\end{tabular}

Berdasarkan Tabel 1 dapat diketahui bahwa dari 35 responden ibu hamil Trimester III terdapat 6 responden dengan pengetahuan kurang, 14 responden dengan pengetahuan cukup, dan 15 responden dengan pengetahuan.

TABLE 2 | Distribusi Frekuensi Perilaku Seks Ibu Hamil Trimester III di Wilayah Kerja Puskesmas Basuki Rahmad

\begin{tabular}{lll}
\hline Perilaku Seks Ibu Hamil & Frekuensi & Persentase (\%) \\
\hline Melakukan & 24 & 68,6 \\
Tidak Melakukan & 11 & 31,4 \\
Total & 35 & 100,0 \\
\hline
\end{tabular}

Berdasarkan Tabel 2 dapat diketahui bahwa dari 35 orang ibu hamil Trimester III terdapat 24 responden yang melakukan hubungan seksual, dan 11 responden yang tidak melakukan hubungan seksual.

Hasil Bivariat

TABLE 3 | Hubungan Pengetahuan dengan Perilaku Seks Ibu Hamil Trimester III di Wilayah Kerja Puskesmas Basuki Rahmad

\begin{tabular}{|c|c|c|c|c|c|c|c|c|}
\hline \multirow{4}{*}{ Pengetah } & \multirow{2}{*}{\multicolumn{2}{|c|}{$\begin{array}{l}\text { Perilaku } \\
{ }_{\mathrm{n} H \text { Hamil }}\end{array}$}} & & $u$ & \multirow{3}{*}{ Total } & \multirow{3}{*}{$\chi^{2}$} & \multirow{4}{*}{$p$} & \multirow{4}{*}{ C } \\
\hline & & & & & & & & \\
\hline & \multicolumn{2}{|c|}{ Melakukan } & \multicolumn{2}{|c|}{$\begin{array}{l}\text { Tidak } \\
\text { Melakukan }\end{array}$} & & & & \\
\hline & $\mathrm{F}$ & $\%$ & $\mathrm{~F}$ & $\%$ & & \multirow{5}{*}{9,833} & & \\
\hline Kurang & 1 & 16,7 & 5 & 83,3 & 6 & & \multirow{4}{*}{0,007} & \multirow{4}{*}{0,468} \\
\hline Cukup & 10 & 71,4 & 4 & 28,6 & 14 & & & \\
\hline Baik & 13 & 86,7 & 2 & 13,3 & 15 & & & \\
\hline Jumlah & 24 & 68,6 & 11 & 31,4 & 35 & & & \\
\hline
\end{tabular}

Berdasarkan Tabel 3 terlihat bahwa dari 6 responden dengan pengetahuan kurang, terdapat 1 responden yang melakukan hubungan seks dan 5 responden yang tidak melakukan hubungan seks, selanjutnya dari 14 responden dengan pengetahuan cukup, terdapat 10 responden melakukan hubungan seks dan 4 responden yang tidak melakukan hubungan seks, serta dari 15 responden yang pengetahuannya baik, terdapat 13 responden orang melakukan hubungan seks dan 2 responden tidak melakukan hubungan seks.

Hasil uji person chi-square didapat sebesar $\left(\mathrm{X}^{2}\right)=9,833$ dengan nilai asymp.sig $(\mathrm{p})=$ $0,007<\alpha=0,05$, berarti signifikan $\mathrm{H}_{0}$ ditolak dan $\mathrm{H}_{a}$ diterima, sehingga dapat disimpulkan 
ada hubungan signifikan antara pengetahuan dengan perilaku seks ibu hamil Trimester III di Wilayah Kerja Puskesmas Basuki Rahmad Kota Bengkulu Tahun 2018. Hasil uji Contingency Coefficient didapat nilai $\mathrm{C}=0,468$, Karena nilai $\mathrm{C}=0,468$ mendekati nilai $\mathrm{C}_{\max }=0,707$ maka dapat disimpulkan bahwa hubungan antara pengetahuan dengan perilaku seks adalah hubungan dengan kategori sedang.

\section{PEMBAHASAN}

Berdasarkan hasil penelitian diperoleh hasi uji person chi-square sebesar $\left(\mathrm{X}^{2}\right)=9,833$ dengan nilai asymp.sig $(\mathrm{p})=0,007<\alpha=0,05$, berarti signifikan $\mathrm{H}_{0}$ ditolak dan $\mathrm{H}_{a}$ diterima, sehingga dapat disimpulkan ada hubungan signifikan antara pengetahuan dengan perilaku seks ibu hamil Trimester III di Wilayah Kerja Puskesmas Basuki Rahmad Kota Bengkulu Tahun 2018. Hasil uji Contingency Coefficient didapat nilai $\mathrm{C}=0,468$, Karena nilai $\mathrm{C}=0,468$ mendekati nilai $\mathrm{C}_{\max }$ $=0,707$ maka dapat disimpulkan bahwa hubungan antara pengetahuan dengan perilaku seks adalah hubungan dengan kategori sedang.

Berdasarkan tabel 1 dapat diketahui bahwa dari 35 responden ibu hamil Trimester III terdapat 6 responden dengan pengetahuan kurang, 14 responden dengan pengetahuan cukup, dan 15 responden dengan pengetahuan baik.

Pengetahuan adalah kesan di dalam pikiran manusia sebagai hasil penggunaan panca inderanya, yang berbeda dengan kepercayaan, takhayul dan penerangan lain yang keliru (Soekanto (2006)). Tingkat pengetahuan merupakan domain yang sangat penting dalam membentuk tindakan seseorang, sedangkan perilaku akan bersifat langgeng apabila didasari oleh pengetahuan dan kesadaran (Notoatmodjo (2010)).

Berdasarkan tabel 2 dapat diketahui bahwa dari 35 orang ibu hamil Trimester III terdapat 24 responden yang melakukan hubungan seksual, dan 11 responden yang tidak melakukan hubungan seksual.

Hubungan seks selama kehamilan merupakan hubungan suami istri yang dilakukan pada masa kehamilan dengan cara atau proses dari hubungan suami istri tersebut, dengan memahami dan mengerti proses dalam hubungan seks selama kehamilan dapat mengurangi kecemasan dan ketakutan pada pasangan. Hal ini sesuai dengan teori bahwa dengan mengerti dan memahami hubungan seks selama kehamilan dapat mengurangi kecemasan dan ketakutan pasangan dalam melakukan hubungan seks selama masa kehamilan (Nugraha and R (2005))

Berdasarkan tabel 3 terlihat bahwa dari 6 responden dengan pengetahuan kurang, terdapat 1 responden yang melakukan hubungan seks dan 5 responden yang tidak melakukan hubungan seks. Berdasarkan hasil penelitian, 1 responden yang melakukan hubungan seksual di kehamilan Trimester III dikarenakan keinginan dari suami dan responden juga nyaman saat berhubungan seksual. Sementara yang tidak melakukan hubungan seksual hal ini dikarenakan beberapa hal. Ada 2 responden yang dikarenakan kurangnya informasi yang didapatkan tentang pentingnya hubungan seksual di kehamilan Trimester III sehingga tidak mengetahui manfaat serta pentingnya melakukan hubungan seksual pada kehamilan Trimester III, kurangnya keinginan ibu untuk mencari informasi diberbagai sumber media maupun mencari informasi pada tenaga kesehatan membuat ibu tidak mau melakukan hubungan seksual. Selain itu 2 responden beralasan tidak melakukan hubungan seksual selama kehamilan Trimester III dikarenakan ibu mempercayai akan mitos yang beredar di masyarakat, yaitu berhubungan seksual selama kehamilan Trimester III dapat menyebabkan bayi lahir premature dan perdarahan. 1 responden lainnya mengatakan tidak nyaman saat melakukan hubungan seksual pada Trimester III dikarenakan bentuk tubuh yang berubah.

Penelitian yang dilakukan oleh Prassana (2012) dalam (Farhani (2014)) menyatakan bahwa kurangnya pengetahuan yang dimiliki oleh ibu karena ibu jarang mencari informasi tentang hubungan seksual selama kehamilan. Pengetahuan ibu hamil tentang hubungan seksualitas kurang maka ibu tidak melakukan hubungan seksual selama kehamilan. Ibu tidak tahu bahwa sebenarnya hubungan seksual selama kehamilan diperbolehkan jika kehamilan ibu sehat dan normal, karena ketidaktahuan tersebut kemudian muncul ketakutan dan kekhawatiran untuk melakukan hubungan seksual. 
Selanjutnya dari 14 responden dengan pengetahuan cukup, terdapat 10 responden melakukan hubungan seks dan 4 responden yang tidak melakukan hubungan seks. 10 responden yang melakukan hubungan seksual, dikarenakan sudah mengetahui tentang pentingnya melakukan hubungan seksual selama kehamilan Trimester III, responden menyatakan melakukan hubungan seksual selama kehamilan Trimester III bisa menambah keharmonisan hubungan rumah tangga bersama suami. Sementara 4 responden yang tidak melakukan hubungan seksual dikarenakan tidak memiliki hasrat untuk melakukan hubungan seksual, bahkan ada 2 responden yang mengatakan memiliki hubungan yang kurang harmonis pada suaminya pada kehamilan Trimester III.

Dari 15 responden yang pengetahuannya baik, terdapat 13 responden orang melakukan hubungan seks dan 2 responden tidak melakukan hubungan seks. Hal ini karena telah mengetahui manfaat dan mempunyai kemauan untuk melakukan hubungan seksual selama kehamilan Trimester III. Responden menyatakan mendapatkan informasi tentang pentingnya melakukan hubungan seksual yang benar selama kehamilan Trimester III dari bidan dan dari tenaga kesehatan yang lain saat memeriksakan kehamilan dan pada saat ibu mengikuti kelas ibu hamil, selain itu juga dari media massa misalnya dari internet, majalah kesehatan, penyuluhan atau acara kelas ibu hamil dan lain-lain. Sementara 2 responden yang tidak melakukan hubungan seks dikarenakan tidak memiliki hasrat untuk melakukan hubungan seksual pada kehamamilan Trimester III dan juga 1 reponden mengaku suami bekerja diluar kota sehingga tidak bisa melakukan hubungan seksual selama kehamilan Trimester III.

Hasil penelitian ini sejalan dengan penelitian (Hapsari and Sudarmiati (2011)) yang menyebutkan bahwa alasan responden tidak melakukan hubungan seks selama kehamilan dikarenakan hasrat istri melakukan hubungan seksual selama kehamilan mengalami perubahan. Menurun di awal kehamilan, meningkat di kehamilan lanjut serta penurunan kembali di kehamilan akhir (Trimester III). Perubahan hasrat hubungan seksual disebabkan oleh perubahan fisik yang dialami oleh ibu hamil seperti, pinggang terasa sakit, perut tertekan ataupun sesak nafas. Selain itu juga dikarenkan adanya mitos atau kepercayaan tentang hubungan seksual saat hamil dari Suku Jawa. Seluruh partisipan menyatakan bahwa terdapat kepercayaan bahwa hubungan seksual saat kehamilan dapat mengakibatkan keguguran.

Hasil penelitian ini juga sejalan dengan penelitian (Pramudawardhani and Shanti (2017)) Berdasarkan hasil penelitian diketahui bahwa 43 responden $(71,7 \%)$ dari 60 responden memiliki tingkatan pengetahuan baik sehingga dapat menyebutkan manfaat hubungan seksual selama kehamilan. Hal ini didukung oleh hasil penelitian dari jawaban kuesioner tentang manfaat hubungan seksual selama kehamilan yaitu hubungan seksual dapat melatih otot panggul, hubungan seksual akan memperlancar peredaran darah, dan hubungan seksual menjadikan kehidupan rumah tangga lebih harmonis.

Berdasarkan hasil penelitian dapat dilihat bahwa semakin baik pengetahuan ibu tentang manfaat dan perilaku seksual selama kehamilan Trimester III maka semakin baik pula minat responden melakukan hubungan seksual pada kehamilan Trimester III. Begitupun sebaliknya, semakin kurang pengetahuan ibu tentang manfaat dari hubungan seksual selama kehamilan Trimester III maka semakin rendah pula minat responden melakukan hubungan seksual selama kehamilan Trimester III.

Pengaruh lingkungan memberikan andil yang cukup besar dalam membentuk pengetahuan ibu hamil tentang seksual selama kehamilan Trimester III. Banyak ibu hamil yang merasa khawatir melakukan hubungan seksual trimester III dikarenakan salahnya informasi yang diterima dari lingkungan sekitar. Selain itu, terdapat beberapa faktor lain yang juga mempengaruhi perilaku seksual ibu hamil Trimester III selain pengetahuan diantaranya unsur mitos sosial budaya dan agama serta kondisi fisik dan psikis ibu hamil trimester III itu sendiri. Oleh karena itu petugas kesehatan diharapkan dapat memberikan informasi yang tepat serta menggali masalah yang ada pada ibu hamil, sehingga ibu hamil lebih terbuka tentang seksualitas selama kehamilan. 


\section{KESIMPULAN}

1. Dari 35 orang responden terdapat 15 orang (42,9\%) ibu hamil di Wilayah Kerja Puskesmas Basuki Rahmad Kota Bengkulu dengan pengetahuan baik.

2. Dari 35 orang responden terdapat 24 orang $(68,6 \%)$ ibu hamil di Wilayah Kerja Puskesmas Basuki Rahmad Kota Bengkulu yang tidak melakukan hubungan seksual.

3. Terdapat hubungan antara pengetahuan dengan perilaku seksual ibu hamil trimester III di Wilayah Kerja Puskesmas Basuki Rahmad Kota Bengkulu, dengan kategori hubungan sedang.

\section{SARAN}

Bagi petugas kesehatan diharapkan agar meningkatkan informasi tentang seksualitas selama kehamilan kepada ibu hamil dengan cara lebih aktif memberikan KIE pada kunjungan pemeriksaan kehamilan maupun penyuluhan pada saat kunjungan posyandu.

\section{REFERENCES}

Cedli, L. G. (2012). Fungsi Seksual Suami Selama Masa Kehamilan Pasangan Skripsi. Skripsi Tidak Dipublikasikan Universitas Indonesia .

Farhani, F. (2014). Hubungan Tingkat Pendidikan dengan Pengetahuan Ibu Hamil Tentang Hubungan Seksual Saat Kehamilan di Wilayah Sukabumi Utara. Skripsi Tidak Dipublikasikan Universitas Islam Negeri Syarif Hidayatullah Jakarta. Available at: epository.uinjkt.

Hapsari, V. D. and Sudarmiati, S. (2011). Pengalaman Seksualitas Ibu Hamil di Puskesmas Pondok Aren Tangerang. Jurnal Ners 6, 76-84.

Hety, D. S. (2016). Presepsi Ibu Primigravida Tentang Hubungan Seksual Selama Kehamilan Trimester III Di Poli Hami Rumah Sakit Bhayangkara Watukosek. Hospital Majapahit (jurnal ilmiah kesehatan politeknik kesehatan majapahit mojokerto) 8, 94-101.

K, I. S. (2013). Buku Ajar Keperawatan Maternitas Dilengkapi Contoh Askep, and others (ed.) (Yogyakarta: Nuha Medika).

Kebidanan, I. (2014). and others (ed.) (Jakarta: PT. Bina Pustaka Sarwono Prawirohardjo).

Kusmiyati, Y. (2010). Perawatan Ibu Hamil, and others (ed.) (Yogyakarta: Fitramaya).

Manuaba, I. B. G. and Dkk (2012). Pengantar Kuliah Obstetri, and others (ed.) (Jakarta: EGC).
Notoatmodjo, S. (2010). Ilmu Perilaku Kesehatan, and others (ed.) (Jakarta: Rhineka Cipta).

Nugraha, A. and R, N. (2005). Kiat Merangsang Kecerdasan Anak (Jakarta: Puspa Swara).

Pramudawardhani, Z. N. and Shanti, E. F. A. (2017). Tingkat Pengetahuan Ibu Hamil Tentang Seksualitas Selama Kehamilan di Puskesmas Piyungan Bantul Yogyakarta. Jurnal Kesehatan "Samodra Ilmu 8, 72-79.

Soekanto, S. (2006). Sosiologi Suatu Pengantar, and others (ed.) (Jakarta: Raja Grapindo Persada).

Conflict of Interest Statement: The authors declare that the research was conducted in the absence of any commercial or financial relationships that could be construed as a potential conflict of interest.

Copyright (c) 2020 Aprilia Ningsih, and Mulyani. This is an open-access article distributed under the terms of the Creative Commons Attribution License (CC BY). The use, distribution or reproduction in other forums is permitted, provided the original author(s) and the copyright owner(s) are credited and that the original publication in this journal is cited, in accordance with accepted academic practice. No use, distribution or reproduction is permitted which does not comply with these terms. 